\title{
Sporulation without aerial mycelium formation on agar medium by Streptomyces bikiniensis HH1, an A-factor-deficient mutant
}

\author{
GÁBOR SZABó* and SÁNDOR VitÁLIS \\ Institute of Biology, University Medical School, Debrecen, 4012 Debrecen, Hungary
}

(Received 21 February 1992; revised 29 May 1992; accepted 17 June 1992)

\begin{abstract}
Streptomyces bikiniensis HH1, an A-factor-deficient mutant that did not form aerial mycelium on agar medium unless supplemented with A-factor, produced spores abundantly within colonies. The spores formed on reproductive branches morphologically similar to aerial hyphae except that they did not emerge from the surface of the colonies. The spores were morphologically more heterogeneous than those formed when A-factor was added.
\end{abstract}

\section{Introduction}

When cultured on a suitable agar medium, Streptomyces spp. develop aerial mycelium prior to spore formation. The aerial branches project out of the substrate, giving rise to a powdery surface appearance (Chater \& Hopwood, 1973). Mutants deficient in A-factor (2isocapryloyl-3R-hydroxymethyl- $\gamma$-butyrolactone), an autoregulating factor discovered by Khokhlov et al. (1973) in Streptomyces griseus, do not form aerial mycelia. The addition of exogenous A-factor to A-factordeficient strains restores spore formation (Khokhlov $\boldsymbol{e t}$ al., 1973; Hara \& Beppu, 1982). 'S. bikiniensis' HH1 (now known to be $S$. griseus) is an A-factor-deficient mutant that neither produces streptomycin nor forms aerial mycelia owing to the lack of DNA sequences (the gene afs $A$ ) responsible for A-factor synthesis (Horinouchi et al., 1984). This paper reports that on agar medium $S$. bikiniensis $\mathrm{HH} 1$ forms conidia without aerial mycelium production.

\section{Methods}

Strains and cultural conditions. S. bikiniensis $\mathrm{HH} 1$ and the parent wildtype $S$. griseus IFO 13350 were sent to us by Dr T. Beppu, University of Tokyo; $S$. griseus bald-10 was obtained from J. C. Ensign, University of Wisconsin. The strains were cultivated on R2YE (Hopwood et al., 1985), on Difco nutrient broth containing $1.7 \%$ agar (Horinouchi et al., 1985), on DM-1 agar (Ensign et al., 1986), on soya-phosphate medium (Vitális \& Szabó, 1969), and on minimal medium (Waksman, 1950) with various carbon and nitrogen additions. Submerged cultivation was carried out at $30,27,25$ and $23^{\circ} \mathrm{C}$ on a horizontal shaking machine (New Brunswick) at a range of oxygenation conditions. A-factor was a

* Author for correspondence. Tel. 365216531. crude ethyl acetate extract standardized with synthetic, crystalline Afactor (obtained from J. C. Ensign).

Light microscopy. The surface of the colonies was examined by reflected light microscopy with a Reichert Zetopan microscope equipped with an epi-illuminating condenser. For this purpose, dark field illumination (Epi 32/0.65 or Epi $45 / 0.65$ objective, green filter) or a Nomarski interference contrast device for epi-illumination $(45 / 0.65$ or $60 / 0.75$ objective) was used. In reflected light every object emerging from the surface (e.g. aerial hyphae) appears strikingly bright in contrast with the objects adhering to the surface of or within the medium.

Hyphae, hyphal fragments and spores in suspension were characterized by positive and negative phase-contrast microscopy with oil immersion (Reichert Zetopan, $\mathrm{Ph}$ 100/1.25 and PhA 100/1.25 objectives). The density of a given object can be determined by consecutive examination with positive and negative phase-contrast microscopy (Francon, 1961). The cytoplasm of spores and reproductive hyphae is denser than that of the vegetative hyphae. Spores are phasebright with positive contrast because of contrast reversion, and their core seems to be dense with negative contrast. However, some apparent 'spores' and reproductive branches that appear phase-bright with positive contrast look 'empty' with negative phase contrast because of their low density. With this method, spores and reproductive branches can be clearly distinguished from vegetative hyphae and abnormal reproductive elements.

In our experience, the distribution of polysaccharides in reproductive hyphae, spores and vegetative hyphae differs. The presence of polysaccharides is characteristic of spores (Vitális et al., 1963; Vitális \& Szabó 1969). The periodic acid-Schiff (PAS) reaction for the detection of polysaccharides was carried out as described by Vitális et al. (1963) and Vitális \& Szabó (1969). Contrast in the preparation was enhanced by using phase contrast microscopy with monochromatic $(578 \mathrm{~nm})$ light. The intensity of the contrast is proportional to the quantity of polysaccharides present (Vitális \& Hellio, 1969).

\section{Results and Discussion}

S. bikiniensis $\mathrm{HH} 1$ did not produce aerial mycelium on solid medium. The addition of A-factor restored aerial 

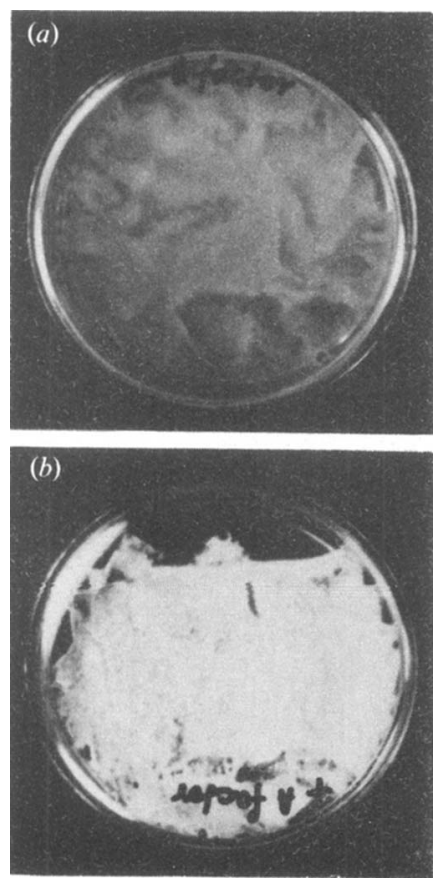

Fig. 1. S. bikiniensis HH1 mutant grown on DM-1 agar (Ensign et al., 1986) without (a) and with (b) A-factor.

mycelium development (Figs 1 and 2). Without A-factor no aerial hyphae could be discerned with the naked eye. By reflected light microscopy (both with dark field illumination and with the Nomarski device) aerial hyphae appear as intense bright parallel lines sometimes with septa (Figs $2 a, c$ and $3 b$, sharp focusing is possible only in a thin layer). With the same method, hyphae which do not project into the air appear as grey reliefs without bright contours (Figs $2 b, 3 a$ ). If large areas of
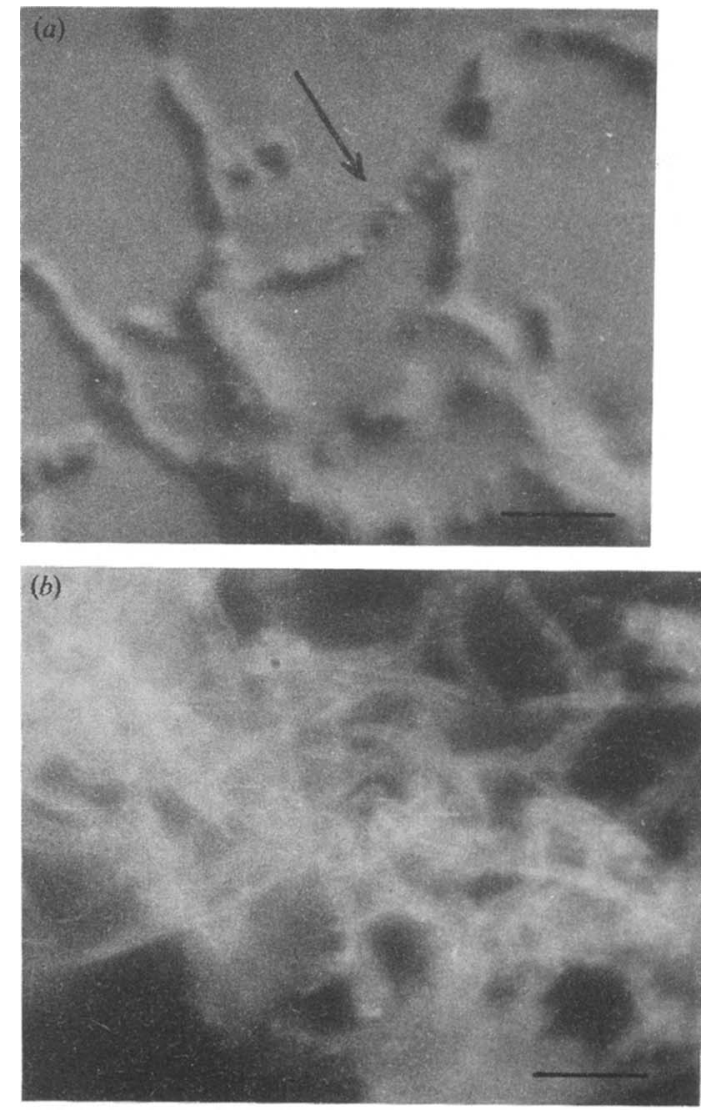

Fig. 3. S. bikiniensis HH1 mutant grown on DM-1-agar; epiillumination Nomarski interference contrast (epi-condenser, Nomarski device and $60 / 0.72$ objective). (a) Control without A-factor. Hyphae are present in the surface layer; in some hyphae prespore-like bodies (arrow) are visible. (b) Culture grown with A-factor. Aerial hyphae emerging above the surface are visible as bright lines on the black background (as in dark-field epi-illumination). The hyphae out of focus are hazy. Bar, $5 \mu \mathrm{m}$.
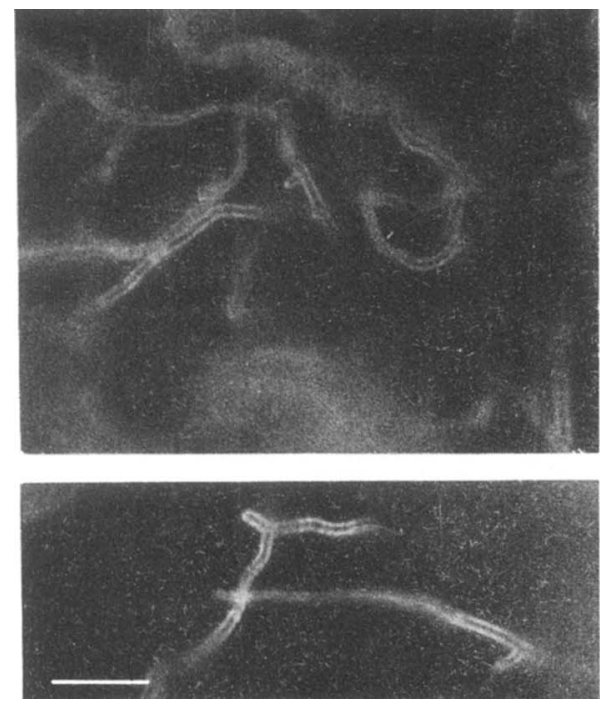

(a)
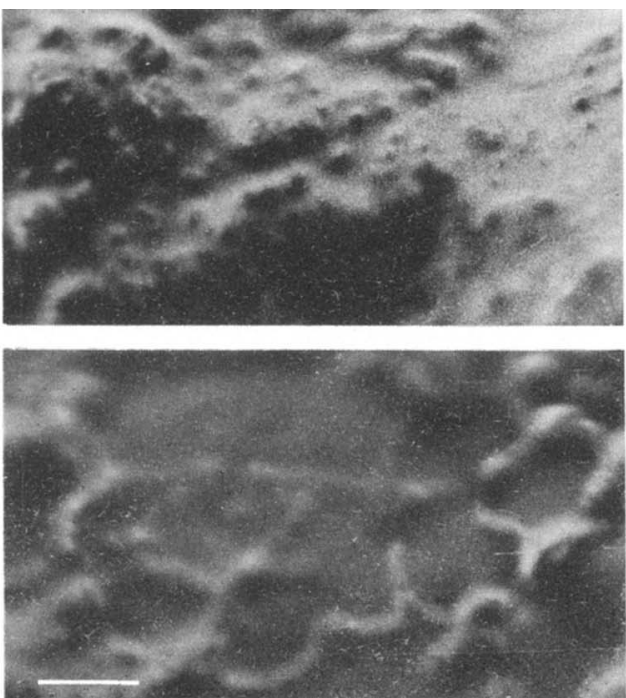

(b)

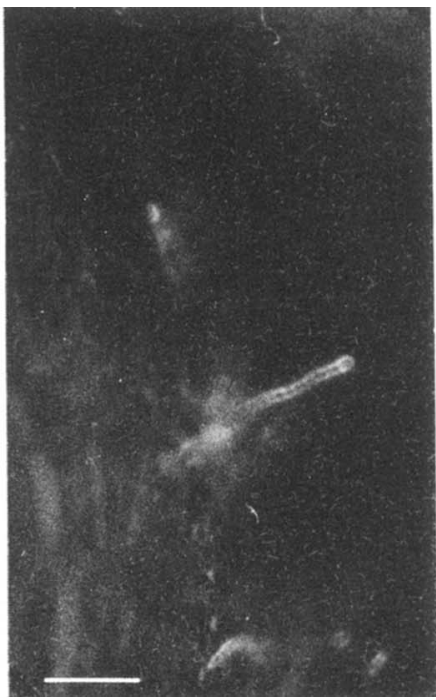

(c) 

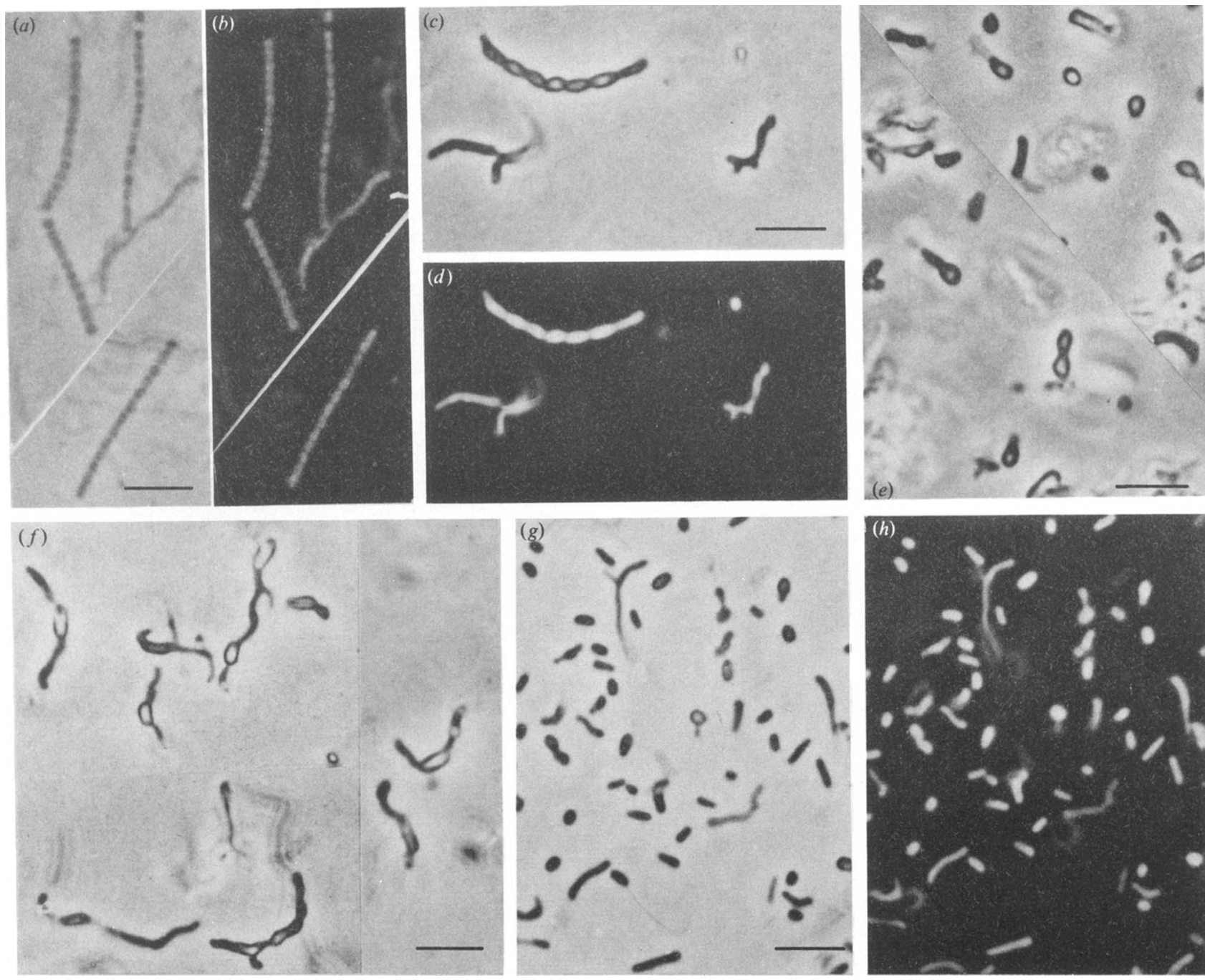

Fig. 4. $(a, b) S$. bikiniensis $\mathrm{HH} 1$ mutant spore chains formed on minimal agar without A-factor but in aerial hypha. Positive and negative phase contrast. Note the small size and non-refractive cytoplasm. (Reichert Zetopan Ph 100 and PhA 100 objectives, oil immersion). ( $c, d$ ) S. bikiniensis HHl spore chain and reproductive branches formed without A-factor in R2YE liquid medium; $122 \mathrm{~h}$ culture; positive and negative phase contrast; oil immersion. Note the large size and highly refractive character of spores (with positive contrast they are phase-bright; with negative contrast their centers are brighter than the walls). (e) Ultrasound-resistant fraction from the culture shown in $c$ and $d$ (only positive contrast is shown). $(f)$ Reproductive branches in $72 \mathrm{~h}$ submerged culture of HH1 strain in R2YE medium; positive contrast, oil immersion. Note the irregular septation. $(g, h) S$. bikiniensis HH1 spores produced on R2YE agar medium without A-factor; ultrasonicated and washed preparation; positive and negative contrast; oil immersion. Nearly regular spores and reproductive hypha fragments can be seen. Bar, $5 \mu \mathrm{m}$.

the Petri dish were examined with the aid of reflected light it was possible to demonstrate that in exceptionally rare visual fields on DM-1 (Ensign et al., 1986) and on minimal medium (Waksman, 1950) with sucrose, individual and very short aerial hyphae jutted out from the substrate mycelium (Fig. 2c). The frequency with which these exceptional hyphae emerged was medium-dependent. There were more of them on minimal medium and DM-1 but almost none on R2YE.

However, if a small piece of a colony that showed no

Fig. 2. (a) S. bikiniensis HH1 mutant grown on DM-1 agar with A-factor; dark field epi-illumination with green filter (Reichert Zetopan Epi 45/0.60 objective). The walls of aerial hyphae stand out from the background as brilliant white lines. Some of them are out of focus and can be seen as white clouds (haze) on the black background. (b) Bald colony surface of control culture of HH1 on R2YE-agar without A-factor. The same technique was used as in $(a)$. (c) S. bikiniensis HH1 mutant grown on DM-1-agar without A-factor. The dark field epi-illumination shows a solitary aerial hypha emerging above the surface of the colony. The cross walls between the pre-spores are visible. (The same Petri-dish as in Fig. 1a. Technique as $a$ and $b$ ). Bar, $10 \mu \mathrm{m}$. 

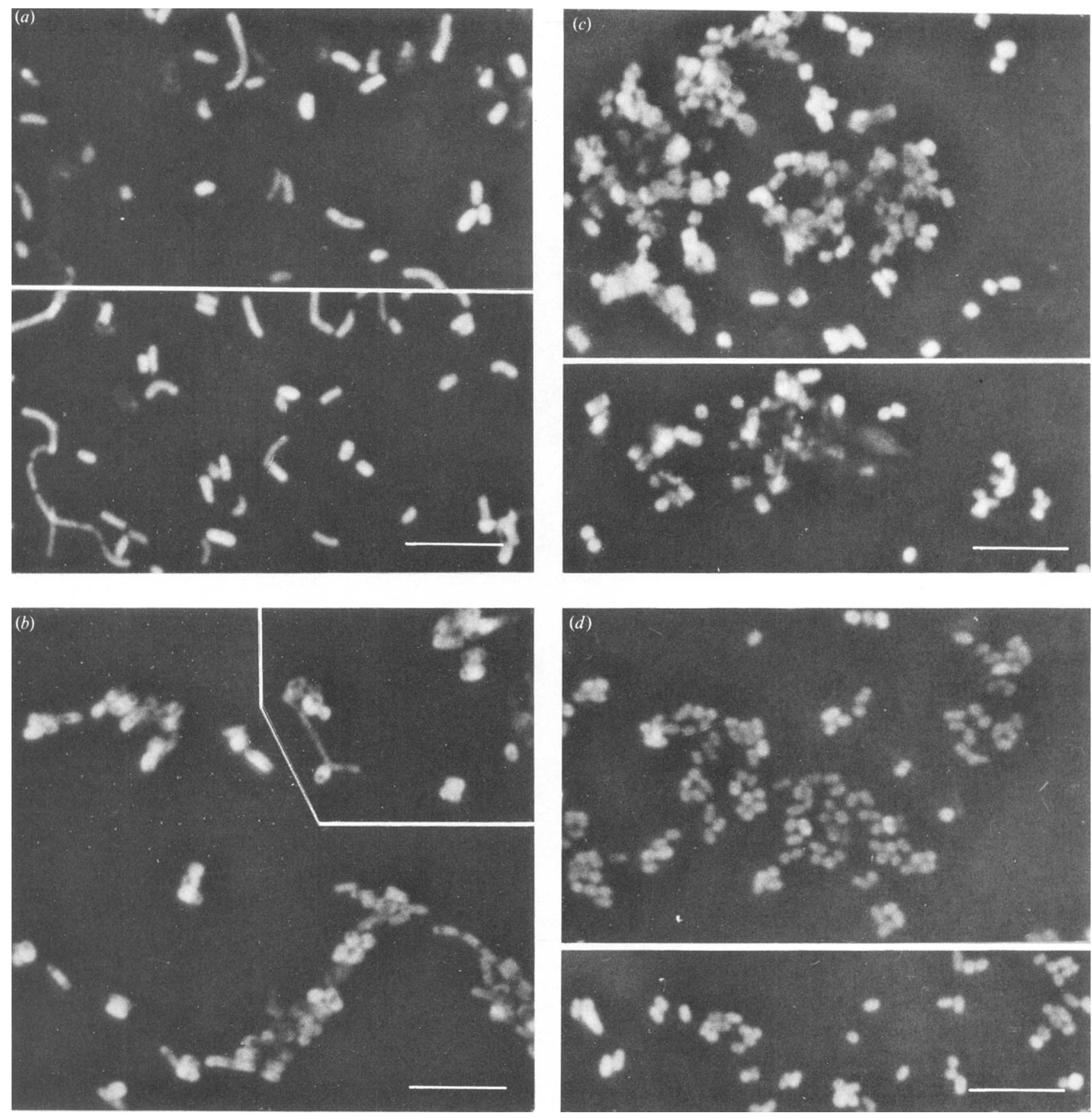

Fig. 5. S. bikiniensis $\mathrm{HHI}$ and $S$. griseus IFO 13350 stained by periodic acid-Schiff reaction for polysaccharides as described by Vitális et al. (1969), negative phase-contrast microscopy. (a) S. bikiniensis HH1 ultrasonicated spores and fragments from R2YE agar without A-factor. (b) S. bikiniensis HH1 ultrasonicated spores and fragments from DM-1 agar without A-factor. (c) S. bikiniensis HH1 ultrasonicated spores and fragments from DM-1 agar with A-factor. (d) $S$. griseus IFO 13350 spores from R2YE agar. Bar, $5 \mu \mathrm{m}$.

sign of aerial hyphae was scraped off, suspended in $0.9 \%$ $\mathrm{NaCl}$ and examined in the microscope, the reproductive type of branching hyphae, hyphal-fragments and numerous conidia were found (Fig. $4 g, h$ ). The reproductive branches and conidia exhibited the characteristics of spore formation (Vitális et al., 1963; Vitális \& Szabó, 1969), both in native (Fig. 4) and stained (Fig. 5) preparations. Reproductive branches and spores developed in the substrate mycelium without the formation of aerial hyphae. 
The shape and size of the conidia formed inside colonies without A-factor (Fig. $4 c-h$ ) were less regular than those formed with A-factor added, or produced in aerial hyphae (Fig. $4 a, b$ and Fig. $5 c, d$ ). They were moderately phase-bright with positive contrast (higher negative contrast verified their higher density).

When the mycelium (confluent growth) from one Petri dish was shaken with glass beads and then washed with $3 \mathrm{ml} 0.9 \% \mathrm{NaCl}$, no less than several tens of millions of spores per ml could be counted using a Buerker chamber. The number of colony forming units conformed to the value predicted by counting.

This type of development with spore formation was also found in submerged cultures (Figs $4 c, f$ ). Lowering the incubation temperature to 27,25 or $23^{\circ} \mathrm{C}$ prolonged the hyphal vegetative growth phase, but did not prevent the formation of reproductive branches and conidia. None of the alterations to the cultivation media or aeration prevented conidia production.

Conidia and fragments obtained from $S$. bikiniensis $\mathrm{HH} 1$ colonies grown on agar medium without A-factor were morphologically and physiologically more heterogeneous (Fig. $4 g, h$ and Fig. $5 a, b$ ) than the conidia produced on aerial hyphae (Fig. $4 a, b$; Fig. $5 c, d$ ). Ultrasonication for $4 \times 20 \mathrm{~s} \mathrm{(1.5} \mathrm{A} \mathrm{with} \mathrm{MSE} \mathrm{Ultrasonic}$ Power Unit no. 3000) of spores and fragments obtained with $\mathrm{A}$-factor absent resulted in a $50 \%$ reduction of colony forming units. Lysozyme treatment $\left(500 \mu \mathrm{g} \mathrm{ml}^{-1}\right)$ for $60 \mathrm{~min}$ at $30^{\circ} \mathrm{C}$ reduced the colony forming units by $40-50 \%$. Incubation at $45^{\circ} \mathrm{C}$ for $60 \mathrm{~min}$ reduced the colony forming units to the same extent. The resistant fraction can be regarded as reproductive fragments and spores.

These results show that lack of A-factor does not prevent reproductive differentiation, even spore formation, although the development of aerial hyphae is blocked. Conidia formation in liquid submerged culture is well known by those working with Streptomyces (Carvajal, 1947; Kendrick \& Ensign, 1983; Vitális et al., 1963). Chater et al. (1990) has also described the development of conidia in the substrate mycelium on agar media (evoked by overproduction of whiG sigma factor). However, this report is the first to describe mass production of spores in Streptomyces colonies that do not produce aerial hyphae. These spores are formed on reproductive branches that are similar to aerial hyphae as judged by their form, the density of their cytoplasm and the distribution of the PAS-positive material (Vitális et al., 1963; Vitális \& Szabó, 1969), except that they do not emerge from the substrate (Fig. 4). Further studies are needed to determine if there are any differences between the two kinds of spore-forming branches and also between normal aerial spores and the ones formed within colonies.
Mass production of spores without aerial mycelium formation was also observed with another A-factor responsive Streptomyces mutant obtained from J. Ensign ( $S$. griseus bald-10 designated SKK 1201, bld ${ }^{-}$afs $A^{-}$by Babcock \& Kendrick, 1988). The results demonstrate that spore production is not necessarily preceded in the developmental sequence by the emergence of aerial mycelium. They draw attention to the fact that lack of aerial mycelium does not necessarily mean a block in spore formation. They also point to the possibility of studying the factors that lead to emergence of hyphae into the air. Contrary to generally accepted views, Afactor (at least in these strains) is not needed for spore production but only for the emergence of aerial hyphae.

We thank Professor T. Beppu and Professor J. C. Ensign for kindly providing the Streptomyces bikiniensis and griseus strains. We are indebted to Klára Plébán and Andrea Kiss for their expert technical assistance. This work was supported by the Hungarian Academy of Sciences.

\section{References}

BABCOCK, M. J. \& KENDRICK, K. E. (1988). Cloning of DNA involved in sporulation of Streptomyces griseus. Journal of Bacteriology 170, 2802-2808

Carvajal, F. (1947). The production of spores in submerged cultures by some Streptomyces. Mycologia 39, 425-440.

Chater, K. F. \& Hopwood, D. A. (1973). Differentiation in actinomycetes. Symposia of the Society for General Microbiology 23, $143-160$.

Chater, K. F., Brian, P., Davis, N. K., Leskiw, B. K., Plaskitt, K. A., Soliveri, J. \& TAN, H. (1990). Developmental pathways in Streptomyces: a comparison with endospore formations in Bacillus. In Genetics of Industrial Microorganisms. Proceedings of the Sixth International Symposium on the Genetics of Industrial Microorganisms, vol. I, pp 373-378. Edited by H. Heslot, J. Davis, J. Florent, L. Bobichon, G. Durand and L. Penasse. Strasbourg: Societé Francaise de Microbiologie.

Ensign, J. C., McBride, M. J., Stoxen, L. J., Bertinuson, A., Pomplun, M. \& Ho, A. (1986). The life cycle of Streptomyces: germination and properties of spores and regulation of sporulation. In Sixth International Symposium on Actinomycete Biology, vol. B, pp 777-790. Edited by G. Szabó, S. Biró \& M. Goodfellow. Debrecen, Hungary: Akadémiai Kiadó.

Francon, M. (1961). Progress in Microscopy. International Series of Monographs on Pure and Applied Biology, vol. 9, chapter II, pp. 64-93. Edited by P. Alexander \& Z. M. Bacq. Oxford: Pergamon Press.

HaRA, O. \& BePpU, T. (1982). Mutants blocked in streptomycin production in Streptomyces griseus - the role of A-factor. Journal of Antibiotics 35, 349-358.

Hopwood, D. A., Bibb, M. J., Chater, K. F., Kieser, T., Bruton, C. J., Kieser, H. M., Lydiate, D. J., Smith, C. P., Ward, J. M. \& SCHREMPF, H. (1985). Genetic Manipulation of Streptomyces: a Laboratory Manual. Norwich, UK: The John Innes Foundation.

HoRINOUCHI, S., KUMADA, Y. \& BEPPU, T. (1984). Unstable genetic determinant of A-factor biosynthesis in streptomycin-producing organisms: cloning and characterization. Journal of Bacteriology 158 , $481-487$.

Horinouchi, S., NishiYama, M., Suzuki, H., Kumada, Y. \& BePpU, T. (1985). The cloned Streptomyces bikiniensis A-factor determinant. Journal of Antibiotics 38, 636-641.

KENDRICK, K. E. \& ENSIGN, J. C. (1983). Sporulation of Streptomyces griseus in submerged culture. Journal of Bacteriology 155, 357-366. 
Khokhlov, A. S., Anisova, L. N., Tovarova, I. I., Kleiner, E. M., Kovalenko, I. V., Krasilnikova, O. I., Kornitskaya, E. Y. \& Pliner, S. A. (1973). Effect of A-factor on the growth of asporogeneous mutant of Streptomyces griseus not producing this factor. Zeitschrift für Allegemeine Mikrobiologie 13, 647-655.

VITÁlis, S. \& Hellio, R. (1969). Principe de la mesure des colorations cytochimique a l'aide du microscope a contraste de phase. Annales de l'Institut Pasteur 117, 231-242.

VITÁLIS, S. \& SzaBó, G. (1969). Cytomorphological effect of factor C in submerged cultures on the hyphae of Streptomyces griseus strain
No.: 52-1. Acta Biologica Academiae Scientiarum Hungaricae 20, 8592.

VItális, S., Szabó, G. \& Vályi-Nagy, T. (1963). Comparison of the morphology of streptomycin-producing and nonproducing strains of Streptomyces griseus. Acta Biologica Academiae Scientiarum Hungaricae 14, 1-15.

Waksman, S. A. (1950). The Actinomycetes, Their Nature, Occurrence, Activity and Importance. Waltham, Mass., U.S.A.: Chronica Botanica. 